\title{
BMJ Open Effects of managed care on the proportion of inappropriate elective diagnostic coronary angiographies in non-emergency patients in Switzerland: a retrospective cross-sectional analysis
}

\author{
Corinne Chmiel, ${ }^{1}$ Oliver Reich, ${ }^{2}$ Andri Signorell, ${ }^{2}$ Stefan Neuner-Jehle, ${ }^{1}$ \\ Thomas Rosemann, ${ }^{1}$ Oliver Senn ${ }^{1}$
}

To cite: Chmiel C, Reich 0 , Signorell A, et al. Effects of managed care on the proportion of inappropriate elective diagnostic coronary angiographies in non-emergency patients in Switzerland: a retrospective crosssectional analysis. BMJ Open 2018;8:e020388. doi:10.1136/ bmjopen-2017-020388

- Prepublication history and additional material for this paper are available online. To view these files, please visit the journal online (http://dx.doi. org/10.1136/bmjopen-2017020388).

Received 31 October 2017 Revised 9 October 2018 Accepted 11 October 2018

Q Check for updates

(c) Author(s) (or their employer(s)) 2018. Re-use permitted under CC BY-NC. No commercial re-use. See rights and permissions. Published by BMJ.

${ }^{1}$ Institute of Primary Care, University of Zurich, Zurich, Switzerland

${ }^{2}$ Department of Health Sciences, Helsana Group, Zurich,

Switzerland

Correspondence to

Dr Corinne Chmiel;

Corinne.Chmiel@usz.ch

\section{ABSTRACT}

Objective Guidelines recommend non-invasive ischaemia testing (NIIT) for the majority of patients with suspected ischaemic heart disease in a non-emergency setting. A substantial number of these patients undergo diagnostic coronary angiography (CA) without therapeutic intervention inappropriately due to lacking preceding NIIT. The aim of this study was to evaluate the effect of voluntary healthcare models with limited access on the proportion of patients without NIIT prior to elective purely diagnostic CA.

Design Retrospective cross-sectional analysis of insurance claims data from 2012 to 2015 . Data included claims of basic and voluntary healthcare models from approximately 1.2 million patients enrolled with the Helsana Insurance Group. Voluntary healthcare models with limited health access are divided into gate keeping (GK) and managed care (MC) capitation models. Inclusion criteria: patients undergoing CA. Exclusion criteria: Patients $<18$ years, incomplete health insurance data coverage, acute cardiac ischaemia and emergency procedures, therapeutic CA (coronary angioplasty/stenting or coronary artery bypass grafting). The effect of voluntary healthcare models on the proportion of NIIT undertaken within 2 months before diagnostic CA was assessed by means of multiple logistic regression analysis, controlled for influencing factors.

Results 9173 patients matched inclusion criteria. 33.2\% (3044) did not receive NIIT before CA. Compared with basic healthcare models, $\mathrm{MC}$ was independently associated with a higher proportion of NIIT ( $p<0.001$, OR 1.17, Cl 1.045 to 1.312), when additionally controlled for demographics, insurance coverage, inpatient treatment, cardiovascular medication, chronic comorbidities, high-risk status (patients with therapeutic cardiac intervention 1 month after or 18 months prior to diagnostic CA). GK models showed no significant association with the rate of NIIT ( $p=0.07$, OR 1.11, Cl 0.991 to 1.253).

Conclusions In a non-GK healthcare system, voluntary MC healthcare models with capitation were associated with a reduced inappropriate use of diagnostic CA compared with GK or basic models.
Strengths and limitations of this study

- Highly relevant topic concerning inappropriate use of a potentially harmful and expensive procedure such as the coronary angiography (CA).

- Only scarce data on non-emergency CA exist in literature originating from different healthcare settings.

- Data originate from a single health insurance group in Switzerland, although one of the largest in the country, including data on health insurance claims from approximately 1.2 million patients.

- No data on socioeconomic status and clinical information are available.

\section{INTRODUCTION}

Existing guidelines ${ }^{1-7}$ recommend non-invasive ischaemia testing (NIIT) for the majority of patients with suspected ischaemic heart disease in a non-emergency setting. Nevertheless, a substantial number of these patients undergo diagnostic coronary angiography (CA) without therapeutic intervention inappropriately and are therefore exposed to unnecessary risks without any clinical benefit. ${ }^{8-15}$ In a non-gate keeping (GK) healthcare system such as Switzerland, hardly any steering mechanisms exist to ensure that potentially harmful and expensive procedures are only performed in case of correct indication. The admitting physician (mainly general practitioner or cardiologist) usually sets the indication for the intervention and the performing invasive centres rarely decline assigned patients due to economic reasons or in order not to disagree with the admitting physician.

Besides the basic healthcare models, offering unlimited access to almost all sectors of the healthcare system including specialist and emergency care, alternative voluntary healthcare models with various degrees of 
restriction in exchange to premium reduction can be chosen from. These voluntary healthcare models can be summarised into two main groups: (1) GK models with steering mechanisms, such as basic consultation of an insurance hotline for example and (2) managed care (MC) models with capitation. Previous studies showed a lower prevalence of potentially inappropriate medication use in elderly patients and a lower disease-specific hospitalisation rate in patients who were chronically ill enrolled in a MC model compared with non-MC patients. ${ }^{16}{ }^{17}$ No data on the association between NIIT and various types of healthcare models in Switzerland exist.

The aim of this study was therefore to evaluate the effect of voluntary GK or MC healthcare models on the proportion of patients without NIIT prior to elective purely diagnostic CA without therapeutic intervention. The study includes a retrospective analysis of insurance claims data on diagnostic procedures undertaken within 2 months before CA depending on the healthcare model.

\section{MATERIALS AND METHODS \\ Setting}

Swiss residents are obliged to enrol in a basic healthcare model, which covers all costs besides deductibles. Depending on the model chosen, annual deductibles for adults vary between 300 and 2500 Swiss Francs. A patient copayment of $10 \%$ of all costs up to a maximum of 700 Swiss Francs per year is payable independent of the chosen healthcare model. Currently, residents can chose a basic healthcare model from 53 different insurance companies. In general, in Switzerland, no gate-keeping system exists, meaning that patients have unlimited access to all healthcare providers, unless they are voluntarily insured in a limited access model. Patients agree to a restriction of choice or limited access in exchange of lower premiums. In such limited access models, the general practitioner or an insurance telephone hotline has to be consulted before contacting a specialist or another institution such as a hospital. In case of emergency, this regulation is over-ruled. In Switzerland, the currently existing limited access models can be summarised into two types of models: (1) GK models with steering mechanisms, such as prior consultation of a telemedicine centre, for example and (2) MC models with capitation. In the capitation system, the health insurance company reimburses the healthcare providers, usually physician networks, with a set amount for each enrolled patient assigned to them per period of time, whether or not that person seeks care. The remuneration is based on the average expected healthcare utilisation of each individual patient, with greater payment for patients with significant medical history or chronic conditions. Compared with other healthcare systems, the Swiss system is more inpatient treatment oriented due to cofinancing of inpatient treatments by governmental institutions.

\section{Subjects, data collection and measurements}

Data for this study included health insurance claims from approximately 1.2 million patients, who live all over
Switzerland and were enrolled with the Helsana Group. Data on patients undergoing CA in the years 2012 to 2015 were retrospectively analysed. Data were considered for analysis if insurance coverage was complete within 18 months before and/or 1 month after CA. A total 828 of 12078 (6.8\%) of patients were not considered due to incomplete coverage of health insurance data during the necessary observation period (due to, eg, change of insurance company, military services, death). Hence, data on 11250 patients remained for analysis before exclusion criteria. Detailed TARMED (Standard billing rate for outpatient medical care in Switzerland, version 2014) and Diagnosis Related Groups (DRG, version 2012) positions are specified in online supplementary appendix 1.

\section{Inclusion criteria}

- Diagnostic CA performed in the years 2012-2015. If in this time interval, patients received more than one $\mathrm{CA}$, only the first CA was taken into consideration $(n=11250)$.

\section{Exclusion criteria}

- Patients $<18$ years.

- Acute cardiac ischaemia and/or emergency procedures.

- Therapeutic CA (coronary angioplasty/stenting or coronary artery bypass grafting).

\section{Measurements}

- Patient characteristics: sex, age, language area and type of insurance coverage (deductible class, supplementary private hospital insurance, MC healthcare model).

- Setting of CA: inpatient or outpatient.

- NIIT performed within 2 months prior to CA (stress-ECG, echocardiography, stress echocardiography, scintigraphy, CT, cardiac MRI).

- Cardiovascular Medication grouped according to Anatomical-Therapeutic-Chemical-Classification $(\mathrm{ATC})^{18}$

- Group 1: aspirin, platelet aggregation inhibitors.

- Group 2: statins, lipid modifying agents.

- Group 3: antihypertensives, diuretics, beta blocking agents, calcium channel blockers, agents acting on the renin-angiotensin system.

- Group 4: antidiabetics.

- Group 5: antianginous drugs.

- Group 6: antithrombotics.

- Number of chronic conditions according to Pharmaceutical cost groups $\mathrm{PCG}^{1920}$

- Group 1: pcg_n<3 0, 1 or 2 PCGs.

- Group 2: pcg_n<5 3 to 4 PCGs.

- Group 3: pcg_n<7 5 to 6 PCGs.

- Group 4: pcg_n $\geq 77$ or more PCGs.

Sensitivity analysis with high-risk patients

We performed a sensitivity analysis of our data by defining a subgroup of patients as high-risk with supposed cardiac disease, if having received therapeutic cardiac 
Table 1 Descriptive statistics of the study population grouped into non-limited and limited access healthcare models (GK and $\mathrm{MC)}$

\begin{tabular}{|c|c|c|c|c|c|c|c|c|c|}
\hline & & & & \multicolumn{6}{|c|}{ Limited access ( $n=3915)$} \\
\hline & \multicolumn{3}{|c|}{ Non-limited access $(n=5258)$} & \multicolumn{3}{|c|}{ GK $(n=1816)$} & \multicolumn{3}{|c|}{ MC (n=2099) } \\
\hline & $\begin{array}{l}\text { No NIIT } \\
(n=1818)\end{array}$ & $\begin{array}{l}\text { With NIIT } \\
(n=3440)\end{array}$ & & $\begin{array}{l}\text { No NIIT } \\
(n=574)\end{array}$ & $\begin{array}{l}\text { With NIIT } \\
(n=1242)\end{array}$ & & $\begin{array}{l}\text { No NIIT } \\
(n=652)\end{array}$ & $\begin{array}{l}\text { With NIIT } \\
(n=1447)\end{array}$ & \\
\hline High-risk (=1) & 1006 & 1692 & 2 & 287 & 577 & 2 & 306 & 644 & 2 \\
\hline Age (mean) & $68.1(12.8)$ & $67.6(10.9)$ & ** 1 & $66.4(12.5)$ & $66.9(10.6)$ & 1 & $66.6(13.1)$ & $66.6(11.4)$ & 1 \\
\hline Sex (female) & 738 & 1351 & 2 & 213 & 483 & 2 & 254 & 547 & 2 \\
\hline Deductible & & & 3 & & & 3 & & & 3 \\
\hline 300 & 1262 & 2355 & & 357 & 743 & & 442 & 962 & \\
\hline 500 & 394 & 749 & & 134 & 310 & & 116 & 290 & \\
\hline 1000 & 45 & 71 & & 26 & 65 & & 28 & 48 & \\
\hline 1500 & 59 & 127 & & 24 & 51 & & 23 & 55 & \\
\hline 2000 & 5 & 14 & & 2 & 14 & & 3 & 16 & \\
\hline 2500 & 53 & 124 & & 31 & 59 & & 40 & 76 & \\
\hline Private & 493 & 925 & 2 & 120 & 288 & 2 & 142 & 316 & 2 \\
\hline Latin & 541 & 1066 & 2 & 195 & 466 & 2 & 55 & 116 & 2 \\
\hline Inpatient & 1166 & 1765 & ***2 & 357 & 584 & $* * *$ & 441 & 798 & $* * *$ \\
\hline ATC 1 & 704 & 1738 & $\star \star \star * 2$ & 219 & 648 & ${ }^{* \star \star 2}$ & 241 & 732 & ${ }^{* * \star 2}$ \\
\hline 2 & 576 & 1216 & ${ }^{* *} 2$ & 175 & 465 & **2 & 195 & 512 & *2 \\
\hline 3 & 1114 & 2192 & 2 & 316 & 755 & $\star \star 2$ & 365 & 931 & $\star \star \star 2$ \\
\hline 4 & 277 & 510 & 2 & 72 & 152 & 2 & 80 & 185 & 2 \\
\hline 5 & 281 & 544 & 2 & 89 & 162 & 2 & 79 & 178 & 2 \\
\hline 6 & 1038 & 2429 & ***2 & 319 & 840 & $\star * \star 2$ & 348 & 985 & $\star \star \star \star 2$ \\
\hline PCG & & & $\star \star 3$ & & & 3 & & & 3 \\
\hline$<3$ & 412 & 768 & & 175 & 372 & & 203 & 444 & \\
\hline $3-4$ & 624 & 1342 & & 200 & 474 & & 221 & 557 & \\
\hline $5-6$ & 478 & 893 & & 145 & 295 & & 150 & 304 & \\
\hline$>6$ & 304 & 437 & & 54 & 101 & & 78 & 142 & \\
\hline
\end{tabular}

Significance no NIIT vs with NIIT within non-limited access and limited access group: ${ }^{* \star *} p<0.0001,{ }^{* \star} p<0.001,{ }^{*} p<0.01$. (1) Kruskal-Wallis test, (2) Fisher exact test, (3) $\chi^{2}$ test, pairwise comparisons between NIIT and no NIIT for each health insurance model separately. ATC, AnatomicalTherapeutic-Chemical-Classification group 1=Aspirin, platelet aggregation inhibitors, $2=$ statins, lipid modifying agents, $3=a n t i h y p e r t e n s i v e s$, diuretics, beta blocking agents, calcium channel blockers, agents acting on the renin-angiotensin system, $4=$ antidiabetics, $5=$ antianginous drugs, 6=antithrombotics (Categorical variable, an individual can be positive for several ATC groups); CA: coronary angiography; GK: gate keeping; Latin, French or Italian part of Switzerland compared to German part; High-risk patients: having received therapeutic cardiac intervention within one month after or 18 months prior to diagnostic CA; MC: managed care: Deductible class in Swiss Francs; NIIT: noninvasive ischaemia testing; PCG: number of chronic conditions according to pharmaceutical cost groups; Private, supplementary private hospital insurance.

intervention/diagnosis within 1 month after and/or 18 months prior to diagnostic CA.

\section{Patient and public involvement}

Neither patients nor the public were involved in the study design.

\section{Statistical analysis}

Descriptive statistical techniques (table 1) were used, to provide a general profile of the study population and grouped into totally three groups of patients: patients with non-limited and limited access healthcare models (GK and MC). The descriptive statistics were performed pairwise for each healthcare model separately. These data were presented as means in the case of continuous variables and as percentages in case of categorical variables.

Differences within the healthcare models (online supplementary appendix 2) with respect to the continuous variable age were analysed with a non-parametric analysis of variance Kruskal-Wallis test. The variables with two levels (sex, high-risk status (patients having received therapeutic cardiac intervention/diagnosis within 1 month after and/or 18 months prior to diagnostic CA), supplementary private hospital insurance coverage, language area, inpatient CA, cardiac medication class 


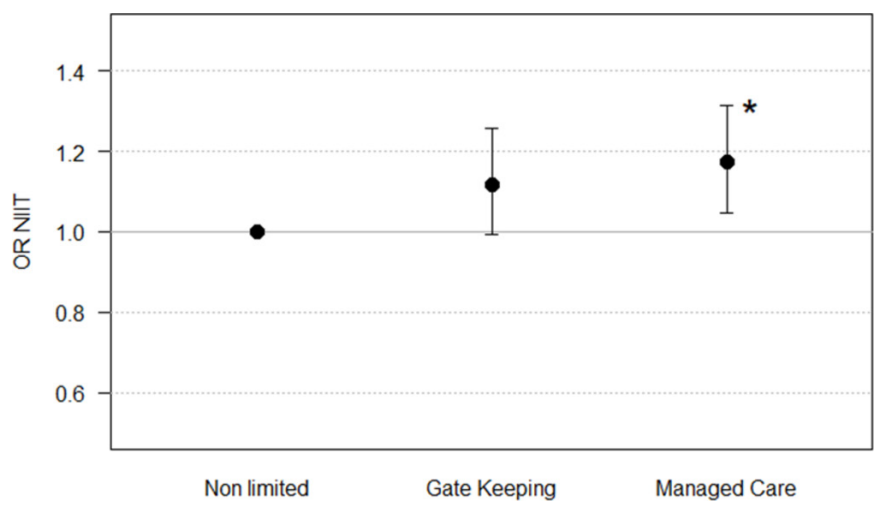

Figure 1 Distribution of NIIT performed according to healthcare model. OR NIIT: OR for NIIT controlled for the confounders age, sex, language area, insurance coverage, inpatient treatment, cardiovascular medication, number of chronic comorbidities and high-risk status. ${ }^{*} \mathrm{P}<0.001$ (OR 1.17) for managed care model compared with non-limited access model (Reference). NIIT, non-invasive ischaemia testing.

according to ATC) were analysed with an exact Fisher's test. The number of chronic medical conditions identified using PCG and the deductible class were compared with a $\chi^{2}$ test.

We performed a logistic regression analysis to evaluate the independent association between receiving NIIT within 2 months prior to $\mathrm{CA}$ and the various healthcare models (figure 1 and table 2). In order to assess patientlevel effects, the following additional independent variables were included in the regression analysis: age, sex, deductible class, supplementary private hospital insurance coverage, language area, inpatient CA, cardiac medication class according to ATC, number of chronic medical conditions identified using PCGs and high-risk status. Goodness of fit measures for the model were: Nagelkerke 0.05075414, BrierScore 0.2134051, C-Statistic 0.618 . The strength of associations was measured by the OR and the respective 95\% CI. The level of significance was set at 0.05 . All statistical analyses were performed using R V.3.3.1 (2016-06-21) (R Foundation for Statistical Computing, Vienna, Austria). ${ }^{21} 22$

\section{Ethics approval}

According to the national ethical and legal regulation, an ethical approval was not needed. Permission to access the study data was provided by the Helsana Group. Since data were anonymised, no consent of patients was required.

\section{RESULTS \\ Population}

During the observed period, a total of 19032 therapeutic CA performed on 14833 patients were registered in the Helsana data warehouse. A total of $11250 \mathrm{CA}$ were eligible for analysis. According to the exclusion criteria (multiple exclusion criteria possible per person therefore the exclusions cannot be summed up), we excluded five patients since they were under the age of 18 years, 360
Table 2 Determinants for receiving non-invasive ischaemia testing before coronary angiography

\begin{tabular}{|c|c|c|c|}
\hline & Cl & OR & Sig \\
\hline Age (years) & 0.998 to 1.007 & 1.003 & \\
\hline Sex (female) & 0.967 to 1.166 & 1.062 & \\
\hline \multicolumn{4}{|c|}{ Deductible Class (Swiss Francs, Reference 300) } \\
\hline 500 & 0.912 to 1.141 & 1.020 & \\
\hline 1000 & 0.667 to 1.120 & 0.865 & \\
\hline 1500 & 0.841 to 1.374 & 1.075 & \\
\hline 2000 & 1.082 to 4.381 & 2.177 & * \\
\hline 2500 & 0.809 to 1.289 & 1.022 & \\
\hline Private & 1.025 to 1.267 & 1.140 & * \\
\hline $\begin{array}{l}\text { French or Italian part } \\
\text { of Switzerland }\end{array}$ & 0.841 to 1.044 & 0.937 & \\
\hline Inpatient CA & 0.540 to 0.664 & 0.599 & $\star \star \star \star ~$ \\
\hline \multicolumn{4}{|l|}{ ATC group 1-6 } \\
\hline 1 & 1.251 to 1.620 & 1.423 & $\star \star \star$ \\
\hline 2 & 0.922 to 1.135 & 1.023 & \\
\hline 3 & 1.002 to 1.218 & 1.104 & * \\
\hline 4 & 0.851 to 1.115 & 0.974 & \\
\hline 5 & 0.874 to 1.130 & 0.994 & \\
\hline 6 & 1.034 to 1.356 & 1.184 & * \\
\hline \multicolumn{4}{|l|}{ PCG (reference<3) } \\
\hline$<5$ & 0.940 to 1.192 & 1.058 & \\
\hline$<7$ & 0.809 to 1.064 & 0.928 & \\
\hline$>=7$ & 0.624 to 0.881 & 0.742 & 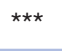 \\
\hline \multicolumn{4}{|c|}{ Limited access models (reference non-limited access) } \\
\hline Managed care & 1.045 to 1.312 & 1.171 & ** \\
\hline Gate keeping & 0.991 to 1.253 & 1.114 & \\
\hline $\begin{array}{l}\text { High-risk cardiac } \\
\text { status }\end{array}$ & 0.046443 & 0.836 & $\star \star \star *$ \\
\hline
\end{tabular}

Sig: significance: ${ }^{\star \star *} \mathrm{p}<0.0001,{ }^{\star *} \mathrm{p}<0.001,{ }^{*} \mathrm{p}<0.01$. ATC:

Anatomical-Therapeutic-Chemical-Classification group 1=Aspirin, platelet aggregation inhibitors, $2=$ statins, lipid modifying agents, $3=$ antihypertensives, diuretics, beta blocking agents, calcium channel blockers, agents acting on the renin-angiotensin system, 4=antidiabetics, $5=$ antianginous drugs, 6 : antithrombotics (Categorical variable, an individual can be positive for several ATC groups); CA: coronary angiography; High-risk patients: having received therapeutic cardiac intervention within one month after or 18 months prior to diagnostic CA; PCG: number of chronic conditions according to pharmaceutical cost groups; Private: supplementary private hospital insurance.

emergency procedures, 1922 therapeutic CA (coronary angioplasty/stenting or coronary artery bypass grafting). In total, 9173 patients remained for analysis.

The descriptive statistics of the study population are listed in table 1. From the 9173 patients representing the study population, 5587 were male $(60.9 \%$, mean age 66.4 years) and 3586 were female $(39.1 \%$, mean age 68.7 years). 
Patients insured in basic healthcare models were slightly older (67.7 (11.6) vs 66.6 (11.6) years, $\mathrm{p}<0.0001)$, chose the lowest possible deductible of 300 Francs more often (3617 (68.8\%) vs $2504(64.0 \%), \mathrm{p}<0.001)$, were enrolled in a supplementary private hospital insurance more often (1418 $(27.0 \%)$ vs $866(22.1 \%), \mathrm{p}<0.0001)$, had more antidiabetics (787 $(15 \%)$ vs $489(12.5 \%), \mathrm{p}<0.0001)$ and antianginal medication (825 (15.7\%) vs $508(13.0 \%)$, $\mathrm{p}<0.0001$ ), more PCGs (4.1 (2.1) vs 3.6 (2.0), $\mathrm{p}<0.0001$ ) and had more often a high-risk status (2696 (51.3\%) vs 1814 (46.3\%), $\mathrm{p}<0.0001)$, compared with patients insured in limited access models (online supplementary appendix 2). Concerning the other patient characteristics, no differences existed.

\section{Non-invasive ischaemia testing}

A total of 3044 patients had no NIIT (1455 without and 1599 with high-risk). Total 488 of 1445 (33.8\%) patients without NIIT had a conventional ECG prior to CA, and in the high-risk population, this was the case in 722 of $1599(45.2 \%) \quad(\mathrm{p}<0.0001$, data not shown). The most NIITs stress-ECG+transthoracic echocardiography were performed significantly more often before CA in patients insured in limited access compared with non-limited access models (1750 (44.7\%) vs $2039(38.8 \%) \mathrm{p}<0.0001$ and $2044(52.2 \%)$ and 2528 (48.1\%), $\mathrm{p}<0.0001$, data not shown). The remaining types of NIIT were rarely performed and only showed a significant difference in the use of scintigraphy (non-limited $131(2.5 \%)$ vs limited access models 64 (1.6\%), $\mathrm{p}<0.001$, data not shown). The distribution of the NIIT is depicted in online supplementary appendix 3 ).

\section{Determinants for non-invasive ischaemia testing}

Patients with MC models had a significantly higher OR of $17 \%$ to receive NIIT before CA compared with patients with non-limited models, when controlled for the confounders age, sex, language area, insurance coverage, inpatient treatment, cardiovascular medication, number of chronic comorbidities and high-risk status (OR 1.17, $\mathrm{p}<0.001)$. GK models did not show any significant influence on the chance of receiving NIIT (OR 1.11, $\mathrm{p}=0.071$ ). The distribution of NIIT performed according to healthcare model can be appreciated in figure 1.

Following determinants were also independently significantly associated with receiving NIIT: the use of platelet aggregation inhibitors, antithrombotic and antihypertensive medication, being supplementary privately insured and a deductible of 2000 SFR. Following determinants were significantly associated with not receiving NIIT: high-risk status, a high number of chronic comorbidities as well as inpatient treatment (table 2).

\section{DISCUSSION}

In our study population of elective CA with no therapeutic consequence (no coronary angioplasty/stenting or coronary artery bypass grafting), one-third did not receive
NIIT before diagnostic CA. MC was independently significantly associated with a higher proportion of NIIT when additionally controlled for potential confounders. GK models showed no significant association with the rate of NIIT.

\section{Effects of limited access healthcare models on treatment quality}

In our study, emergency CA were excluded and the study population consisted of patients undergoing purely diagnostic elective CA with no therapeutic consequence (eg, no coronary angioplasty/stenting or coronary artery bypass grafting). The study population therefore represents a selection of patients with at least stable coronary heart disease (CHD) or no CHD at all. From a previous study among this selection of patients we know, that $37.5 \%$ did not receive any NIIT at all before elective CA with no therapeutic consequence, suggesting a substantial overuse of a potentially harmful and inappropriate diagnostic intervention. ${ }^{12}$ It has been assumed that patients insured in limited access healthcare models undergo less diagnostic procedures or interventions due to budget considerations, especially in capitated healthcare models. In our study, this hypothesis is clearly refuted. Patients with stable angina pectoris insured in limited access healthcare models underwent a more appropriate diagnostic pathway than regularly insured patients did, meaning in a stable clinical situation they were subjected to significantly more non-invasive diagnostic testing, therefore reducing inadequate CA. Our findings are in line with another study from the Swiss healthcare system, which also showed higher referral rates among $\mathrm{MC}$ patients compared with patients insured in basic healthcare models. ${ }^{23}$ One reason for the more appropriate diagnostic pathway found in MC patients might be the aspect of membership in a general practitioners network. In most parts of Switzerland, general practitioners can only offer MC insurance models to their patients, if they are member in a general practitioners network. These networks offer evidence-based guidelines, which the general practitioners are obliged to respect when initiating treatment. Depending on the network, more or less rigorous quality control mechanisms exist to check whether the guidelines are followed, when applicable. General practitioners, who are not member in a network, therefore are less bound to evidence-based treatment pathways. Other studies showed that being insured in $\mathrm{MC}$ models is associated with a survival benefit by promoting better preventive and higher quality of care. ${ }^{24-26}$ Especially among Medicare beneficiaries, which are prone to multimorbidity, this effect has been shown. ${ }^{27}$ These models have also shown lower prevalence of potentially inappropriate medication use in elderly patients and a lower disease-specific hospitalisation rate in patients who were chronically ill. ${ }^{16} 17$

Our study raises the question why patients in limited access healthcare models receive a more appropriate diagnostic pathway in this clinical situation of stable angina 
pectoris. There has been evidence for and against the theory that patients enrolled in a MC healthcare model are healthier due to biased selection ${ }^{28-37}$ and commercial considerations of the MC insurer. ${ }^{38}{ }^{39}$ In our study population, patients insured in limited access models showed some evidence of being healthier than regularly insured patients. Nevertheless, being insured only in MC but not GK models was independently associated with a higher rate of NIIT, controlled for all the differences in patient characteristics. It is clear that physicians participating in MC models are obliged to keep diagnostic and treatment costs as low as possible while keeping up with quality concerns. One could therefore argue that it is cheaper to not to choose a diagnostic detour over NIIT instead of choosing the straight forward way of sending a patient to the more invasive $\mathrm{CA}$, which offers a clear answer to an uncertain clinical situation including the option of therapeutic action. It seems that MC healthcare providers have understood what Meara et al have summed up accurately: 'Reductions in spending for patients must be a result of decreases in the provision of services. If these are needed services, quality of care will decline. Alternatively, quality of care might be higher in low expenditure areas if differences in spending result from reductions in unnecessary or inappropriate services ${ }^{40}$. Besides this intuitive statement, there has been scientific evidence that a diagnostic detour is worthwhile taking, since it sums up in reduced peri-interventional and postinterventional costs without loss in quality. ${ }^{11}$ Our study is not able to answer the questions why patients in limited access models received a more appropriate diagnostic approach. One can only hypothesise that a more rigorous coordination of care, as performed in the MC models, is straighter forward and the indication for invasive and expensive diagnostic procedures is more thoroughly scrutinised.

\section{Determinants for NIIT}

Even though simple echocardiography with no stress testing does not actually qualify as a NIIT, we chose to include this diagnostic procedure due to following considerations: some cardiologists might argue that patients with dyskinesia in simple echocardiography are likely to have relevant coronary pathology therefore offering an argument for CA besides the clinical evaluation. Our theory is supported by the '2014 ESC/EACTS Guidelines on Myocardial Revascularization which state: 'regional wall motion abnormalities may be detected in simple echocardiography, which increase the likelihood of coronary artery disease'.

Since our study lacks clinical data, only indirect hints by means of PCG and ATC codes as well as other confounders are available to assess clinical reasoning. The association between the use of platelet aggregation inhibitors or antithrombotic agents and antihypertensive medication with receiving NIIT before CA suggest a reasonable deliberation in the sense of estimating pretest probability when deciding on optimal diagnostic strategy. The same counts for the association of high-risk status and a larger number of chronic comorbidities as determinants for not receiving NIIT prior to elective CA. This finding is consistent with two US studies indicating that risk stratification was performed, considering the higher likelihood of a coronary pathology in patients with known coronary heart disease. ${ }^{8}{ }^{10}$ In our study, also non-clinical factors seem to influence decision-making processes concerning diagnostic pathways, reflected by the findings that being privately insured and a deductible of 2000 SFR were positively and inpatient treatment negatively independently associated with NIIT.

As previously observed in another Swiss study analysing inappropriate use of arthroscopic meniscal surgery in degenerative knee disease, ${ }^{41}$ a substantial amount of the patients in our sample underwent CA as inpatients in contrast to other healthcare settings. This finding is most likely explained by differences in the organisation of the healthcare system in Switzerland. Here, regional governments subsidise inpatient treatment covering approximately $50 \%$ of total costs, and patients with supplementary private insurance receive a substantially higher reimbursement when treated as inpatients. Nevertheless, in the regression analysis with the outcome proportion of NIIT, we controlled for potential confounders, such as inpatient treatment as well. The results therefore seem robust concerning the question whether limited access healthcare models have a significant impact on the appropriateness of the diagnostic approach.

\section{Reinforcing quality control mechanisms in a non-gate keeping healthcare system}

Besides the existing voluntary steering mechanisms such limited access healthcare models guided by patient's preferences only, more alternative steering mechanisms have to be implemented in non-GK healthcare systems, in order to minimise the influence of non-clinical factors on medical decision making, which might lead to inappropriate and possibly dangerous healthcare utilisation as well as increasing expenditures. A positive example for alternative steering mechanisms is the implementation of national registries ${ }^{42}$ combined with quality initiatives, such as in 2009 published Appropriate Use Criteria for Coronary Revascularization. ${ }^{42} 43$ In 2011, the registry started giving feedbacks on the participating hospital's performance concerning appropriateness of CA including a benchmarking against other participating institutions. At the same time, the American Board of Internal Medicine's Choosing Wisely initiative launched national quality improvement campaigns, identifying CA appropriateness as a key area for intervention. ${ }^{44}$ As a consequence, insurance companies incorporated measures of CA appropriateness into pay-for-performance programmes ${ }^{45}$ and reimbursement was declined for certain CA identified as inappropriate. ${ }^{46}$ The combination of implementing national registries combined with quality initiatives had been proven amazingly effective, showing a decrease of non-acute CA classified as inappropriate from $26.2 \%$ 
to $13.3 \% .^{47}$ In Switzerland, currently no registries on CA exist, hence other solutions for influencing treatment pathways have to be developed, besides offering voluntary limited access healthcare models. A possible alternative solution to the conundrum of reducing costs without cutting quality seems hence to be paying for outcomes instead of volume. As the findings of our study suggest, a possible approach is to raise the market share of MC to such a volume that it might also affect care for fee-for-service patients. ${ }^{40}$ As Meara et al have summarised, the effects have been show to play in a variety of ways: more MC in a market might lower expenditures by reducing the number of specialists, and thereby the number of specialists' services provided $^{48} 49$ by encouraging more conservative practice patterns ${ }^{48} 49$ or by slowing the diffusion of more costly technologies. ${ }^{4850}$

\section{Strengths and limitations}

Only scarce data on non-emergency CA exist in literature. The only data found originates from the USA among Medicare as well as commercially insured patients and from Switzerland, both non-GK healthcare systems. Whether the proportion of inappropriate diagnostic CA from our study can be translated to other non-GK healthcare systems is difficult to estimate, since substantial variation in the proportion of non-acute PCIs considered inappropriate across hospitals can be found, ranging from about $6 \%$ to $70 \% .810141547$ From a previous study from Switzerland, ${ }^{12}$ similar proportions were found, suggesting generalisability of our data. The current study seems even more representative than the previous Swiss study, since it included data over a longer time-period with consecutively larger number of patients and corresponding data. Nevertheless, caution should be used when generalising to larger populations due to the data being limited to only one, even if the largest health insurance company in Switzerland, due to exclusion criteria and the retrospective study design. Since the study is based on insurance claims data, no data on socioeconomic status and clinical information are available. Given that this is a cross-sectional observational study, rather than an interventional one, the only conclusions that we can draw are of association rather than causation. Due to the study design, unfortunately no estimations on clinical outcome parameters can be made. For example, in order to explore clinical appropriateness, the proportion of CA's avoided by performing NIIT would be of great interest. As a substitute for clinical data, ATC and PCG are used, offering only indirect information on comorbidities. On the other hand, PCGs represent a strength, since they have been shown to directly correlate with associated healthcare costs. ${ }^{19}$ Due to data structure, it is not possible to distinguish between CT angiography (including intravenous contrast) and CT without intravenous contrast. Therefore, all CTs of the chest were included in analysis.

\section{CONCLUSION}

In a non-GK healthcare system, voluntary MC healthcare models with capitation were associated with a reduced inappropriate use of diagnostic CA compared with GK or basic models.

Contributors Conceived and designed the experiments: CC, OR, AS, SN-J, TR, OS. Performed the experiments: CC, OR, AS. Analysed the data: CC, OR, AS, SN-J, TR, OS. Wrote the paper: CC. Edited and approved the paper: CC, OR, AS, SN-J, TR, OS.

Funding This work was supported by the Swiss Academy of Medical Sciences (SAMS), Switzerland.

Competing interests OR and AS are employed by the Helsana Group.

Patient consent Not required.

Provenance and peer review Not commissioned; externally peer reviewed.

Data sharing statement Individual data cannot be made fully available on the internet because the study is based on claims data of the Helsana Group, the owner of the data. Thus, data underlie data protection and privacy restrictions. These restrictions prohibit the insurer from sharing the collected data. Data analysis was performed within the premises of the Helsana research group by the statistician AS in collaboration with the authors $\mathrm{OR}$ and $\mathrm{CC}$ and administrative permission was received to access deidentified data by the researchers from the University of Zurich.

Open access This is an open access article distributed in accordance with the Creative Commons Attribution Non Commercial (CC BY-NC 4.0) license, which permits others to distribute, remix, adapt, build upon this work non-commercially, and license their derivative works on different terms, provided the original work is properly cited, appropriate credit is given, any changes made indicated, and the use is non-commercial. See: http://creativecommons.org/licenses/by-nc/4.0/.

\section{REFERENCES}

1. Fihn SD, Gardin JM, Abrams J, et al. 2012 ACCF/AHA/ACP/AATS/ PCNA/SCAI/STS guideline for the diagnosis and management of patients with stable ischemic heart disease: executive summary: a report of the American College of Cardiology Foundation/American Heart Association task force on practice guidelines, and the American College of Physicians, American Association for Thoracic Surgery, Preventive Cardiovascular Nurses Association, Society for Cardiovascular Angiography and Interventions, and Society of Thoracic Surgeons. Circulation 2012;126:3097-137.

2. Skinner JS, Smeeth L, Kendall JM, et al. NICE guidance. Chest pain of recent onset: assessment and diagnosis of recent onset chest pain or discomfort of suspected cardiac origin. Heart 2010;96:974-8.

3. National Clinical Guideline Centre for Acute and Chronic Conditions. Chest pain of recent onset: assessment and diagnosis of recent onset chest pain or discomfort of suspected cardiac origin. London: Royal College of Physicians, 2010.

4. Montalescot G, Sechtem U, Achenbach S, et al. 2013 ESC guidelines on the management of stable coronary artery disease: the Task Force on the management of stable coronary artery disease of the European Society of Cardiology. Eur Heart J 2013;34:2949-3003.

5. Archbold RA. Comparison between National Institute for Health and Care Excellence (NICE) and European Society of Cardiology (ESC) guidelines for the diagnosis and management of stable angina: implications for clinical practice. Open Heart 2016;3:e000406.

6. Henderson RA, O'Flynn N; Guideline Development Group. Management of stable angina: summary of NICE guidance. Heart 2012;98:500-7.

7. O' Flynn N, Timmis A, Henderson R, et al. Management of stable angina: summary of NICE guidance. BMJ 2011;343:d4147.

8. Lin GA, Dudley RA, Lucas FL, et al. Frequency of stress testing to document ischemia prior to elective percutaneous coronary intervention. JAMA 2008;300:1765-73.

9. Patel MR, Dehmer GJ, Hirshfeld JW, et al. ACCF/SCAI/STS/ AATS/AHA/ASNC 2009 Appropriateness Criteria for Coronary Revascularization: A Report of the American College of Cardiology Foundation Appropriateness Criteria Task Force, Society for Cardiovascular Angiography and Interventions, Society of Thoracic Surgeons, American Association for Thoracic Surgery, American Heart Association, and the American Society of Nuclear Cardiology: Endorsed by the American Society of Echocardiography, the Heart 
Failure Society of America, and the Society of Cardiovascular Computed Tomography. Circulation 2009;119:1330-52.

10. Topol EJ, Ellis SG, Cosgrove DM, et al. Analysis of coronary angioplasty practice in the United States with an insurance-claims data base. Circulation 1993;87:1489-97.

11. Shaw LJ, Hachamovitch R, Berman DS, et al. The economic consequences of available diagnostic and prognostic strategies for the evaluation of stable angina patients: an observational assessment of the value of precatheterization ischemia. Economics of Noninvasive Diagnosis (END) Multicenter Study Group. J Am Coll Cardiol 1999;33:661-9.

12. Chmiel C, Reich O, Signorell A, et al. Appropriateness of diagnostic coronary angiography as a measure of cardiac ischemia testing in non-emergency patients - a retrospective cross-sectional analysis. PLoS One 2015;10:e0117172.

13. Boden WE, O'Rourke RA, Teo KK, et al. Optimal medical therapy with or without $\mathrm{PCl}$ for stable coronary disease. N Engl J Med 2007;356:1503-16.

14. Chan PS, Patel MR, Klein LW, et al. Appropriateness of percutaneous coronary intervention. JAMA 2011;306:53-61.

15. Bradley SM, Maynard C, Bryson CL. Appropriateness of percutaneous coronary interventions in Washington State. Circ Cardiovasc Qual Outcomes 2012;5:445-53.

16. Reich O, Rosemann T, Rapold R, et al. Potentially inappropriate medication use in older patients in Swiss managed care plans: prevalence, determinants and association with hospitalization. PLOS One 2014;9:e105425.

17. Huber CA, Reich O, Früh M, et al. Effects of integrated care on disease-related hospitalisation and healthcare costs in patients with diabetes, cardiovascular diseases and respiratory illnesses: a propensity-matched cohort study in Switzerland. Int J Integr Care 2016;16:11

18. Huber CA, Szucs TD, Rapold R, et al. Identifying patients with chronic conditions using pharmacy data in Switzerland: an updated mapping approach to the classification of medications. BMC Public Health 2013;13:1030.

19. Lamers LM, van Vliet RC. The Pharmacy-based Cost Group model: validating and adjusting the classification of medications for chronic conditions to the Dutch situation. Health Policy 2004;68:113-21.

20. Huber CA, Schneeweiss S, Signorell A, et al. Improved prediction of medical expenditures and health care utilization using an updated chronic disease score and claims data. J Clin Epidemiol 2013;66:1118-27.

21. RCT. A language and environment for statistical computing $R$ Foundation for Statistical Computing, Vienna, Austria: R, 2015 Available from. http://www.R-project.org/.

22. A S. DescTools: Tools for descriptive statistics. $R$ package version 0.99 .15 [program, 2016.

23. Tandjung R, Morell S, Hanhart A, et al. Referral determinants in Swiss primary care with a special focus on managed care. PLoS One 2017;12:e0186307.

24. DeLaet DE, Shea S, Carrasquillo O. Receipt of preventive services among privately insured minorities in managed care versus fee-forservice insurance plans. J Gen Intern Med 2002;17:451-7.

25. Landon BE, Zaslavsky AM, Bernard SL, et al. Comparison of performance of traditional Medicare vs Medicare managed care. JAMA 2004;291:1744-52.

26. Miller RH, Luft HS. HMO plan performance update: an analysis of the literature, 1997-2001. Health Aff 2002;21:63-86.

27. Huesch MD. Long-term impact of Medicare managed care on patients treated for coronary artery disease. Med Care 2012;50:18-26.

28. Maciejewski ML, Dowd B, Call KT, et al. Comparing mortality and time until death for medicare $\mathrm{HMO}$ and FFS beneficiaries. Health Serv Res 2001;35:1245-65.
29. Park E. Informing the debate about curbing Medicare Advantage overpayments. Center on Budget and Policy Priorities 2007.

30. Call KT, Dowd B, Feldman R, et al. Selection experiences in Medicare HMOs: pre-enrollment expenditures. Health Care Financ Rev 1999;20:197-209.

31. Deb P, Trivedi PK. Specification and simulated likelihood estimation of a non-normal treatment-outcome model with selection: Application to health care utilization. Econom J 2006;9:307-31.

32. Mello MM, Stearns SC, Norton EC. Do Medicare HMOs still reduce health services use after controlling for selection bias? Health Econ 2002;11:323-40.

33. Cao Z, McGuire TG. Service-level selection by HMOs in Medicare. $J$ Health Econ 2003;22:915-31.

34. Nicholson S, Bundorf $\mathrm{K}$, Stein RM, et al. The magnitude and nature of risk selection in employer-sponsored health plans. Health Serv Res 2004;39:1817-38.

35. Chernew M, Decicca P, Town R. Managed care and medical expenditures of Medicare beneficiaries. $J$ Health Econ 2008;27:1451-61.

36. Atherly A, Dowd BE, Feldman R. The effect of benefits, premiums, and health risk on health plan choice in the Medicare program. Health Serv Res 2004;39:847-64.

37. Huesch MD. Managing care? Medicare managed care and patient use of cardiologists. Health Serv Res 2010;45:329-54.

38. Bundorf MK, Schulman KA, Stafford JA, et al. Impact of managed care on the treatment, costs, and outcomes of fee-for-service Medicare patients with acute myocardial infarction. Health Serv Res 2004;39:131-52.

39. Cutler DM, McClellan M, Newhouse JP. How does managed care do it? Rand J Econ 2000;31:526-48.

40. Meara E, Landrum MB, Ayanian JZ, et al. The effect of managed care market share on appropriate use of coronary angiography among traditional Medicare beneficiaries. Inquiry 2004;41:144-58.

41. Muheim LLS, Senn O, Fruh M, et al. Inappropriate use of arthroscopic meniscal surgery in degenerative knee disease An observational study from Switzerland. Acta Orthop 2017;88:550-5.

42. Registry ACoCC. National Cardiovascular Data Registry.

43. website JC. Proceedings from the National Summit on Overuse 2012. http://www.jointcommission.org/assets/1/6/National_Summit_ Overuse.pdf (accessed August 17 2016).

44. Interventions. SfCAa. Five things physicians and patients should question. http://www.choosingwisely.org/societies/society-forcardiovascular-angiography-and-interventions/ (accessed August 17 2016).

45. Michigan. BCBSo. Hospital Pay-for-Performance Program. https:// www.bcbsm.com/content/dam/public/Providers/Documents/value/ p4p-hospital-cqi-performance-index-guide.pdf (accessed August 17 2016).

46. Department of Health. New York State Medicaid Update. https:// www.health.ny.gov/health_care/medicaid/program/update/2013/ 2013-06.htm\#ous (accessed 17 Aug 2016).

47. Desai N, Bradley S, Parzynski C, et al. Appropriate Use Criteria for Coronary Revascularization and Trends in Utilization, PatientSelection, and Appropriateness of Percutaneous Coronary Intervention - FindingsFrom the NCDR- CathPCI Registry. Circulation 2015;132:2278-78.

48. Baker LC. Managed care and technology adoption in health care: evidence from magnetic resonance imaging. $J$ Health Econ 2001;20:395-421.

49. Heidenreich PA, McClellan M, Frances C, et al. The relation between managed care market share and the treatment of elderly fee-for-service patients with myocardial infarction. Am J Med 2002;112:176-82.

50. Cutler DM, Sheiner L. Managed care and the growth of medical expenditures. Forum Health Econ Policy 1998;1:77-115. 